\title{
Can Forest Management Benefit From Incentives?
}

The industrial revolution in Canadian forestry is upon us. Pulp mills and paper mills are burgeoning across the country, new sawmills and plywood plants are springing up and large, integrated forest products industries are taking shape in heretofore untapped forest areas. All this is resulting in unprecedented pressures on the national allowable cut and some forecasts indicate that demands will outstrip supplies by the year 2000 . The prospect of a wood shortage, together with the likelihood of increasingly expensive wood supplies, is causing some provincial and industrial authorities to take a hard look at the possibility of easing, if not overcoming, such an eventuality. As a result, there are examples of considerable energy being applied to improving the accessibility of remote stands and of initiative aimed at providing for an economical supply of sufficient wood material for the future. This initiative is expressing itself in some provinces through enlightened resource legislation that offers incentives for improved management practices. An example of this legislation is the B.C. Forest Service ruling which permits land-classification activities to be written of $f$ against stumpage charges on selected areas of the Vancouver Island and coastal forests. To date, two companies have taken advantage of this legislation. A further example is an enlightened piece of Alberta legislation with encourages the forest manager to undertake an increasingly intensive management program. The resultant increase in allowable cut over and above his land's natural productivity accrues to the operator free of stumpage charges.

At the time when increased pressure is being brought to bear on our forests to deliver raw wood to an omnivorous forest industry and at a time when multiple use of forest land brings an attendant reduction in productivity, Canada badly needs more of the kind of forestry legislation that is designed to encourage land owners and forest operators to use their ingenuity to increase the yield from their holdings. Our governments, both federal and provincial, must be encouraged to accept the fact that their responsibility is to create an environment in which our forest industries that are dependent upon wood from both publicly and privately-owned lands can not only flourish, but in which they will eagerly participate. At the same time the enabling legislation should be such that it would be folly not to participate. Through the medium of incentives such an environment can be created without damaging any of the Crown's equity. Incentives as stimulants in the renewable resource field make very good sense and provide the ideal instrument for effective teamwork between the Crown and private enterprise. The situation results wherein we can all have our cake and eat it too!

Your Forest Management Committee has undertaken over the past year to uncover and debate suggestions for incentive programs, the purpose of which is to improve forest management in Canada. On the basis of these deliberations a resolution will be presented at the Annual Meeting in October to encourage the Canadian Institute of Forestry to bring the current need for an incentive program to the attention of forest authorities throughout the country. It is to be hoped that a strong mandate will result to carry the proposal to Ministers in the Provincial and Federal governments.

Incentives can be the key to the increased flow of raw wood from managed forest lands. The opportunity to effect significant increases in yields is all that we need to demonstrate whether or not we have the right to regard ourselves as professionals.

D. I. Crossley, Chairman, Technical Affairs Committee on Forest Management.
Editor

G. F. Weetman

570 St. John's Rd.,

Pointe Claire, P.Q.

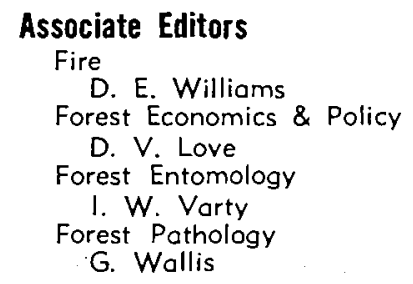

\author{
Forest Products \\ R. H. J. Creighton \\ Forest Management \\ G. F. Weetman \\ Logging \\ H. I. Winer \\ Silviculture \\ R. J. Day \\ D. Glew \\ Wildlife \\ D. H. Pimlott \\ French Associate Editor \\ H. LeBlanc
}

Published bi-monthly by the Canadian Institute of Forestry - Institut Forestier du Canada. Address all corresponoence concerning business matters to $A$. G. Racey, Secretary-Manager, P.Q. Box 5000 , Macdonald College, P.Q., Canada. Subscription rates $\$ 8.00$ per year. $\$ 2.00$ single copies. Refurn postage guaran teed.

The Institute assumes no responsibility for the statements and opinions exressed by contributors. There is a $\$ 40$ per page charge for articles on the results of research. This charge is only made when the supporting agency has
allocated funds for publication. 